ISSN 2073-1558 online version: http://epub.oeaw.ac.at/eco.mont

\title{
Administration and management effectiveness of protected areas: stakeholders' views of Dadia National Park, Greece
}

\section{Veronika Andrea, Stilianos Tampakis, Georgios Tsantopoulos \& Garyfallos Arabatzis}

Keywords: administration, management, stakeholders, Evros Prefecture, national parks, protected areas, environmental policy

\section{Abstract}

The management effectiveness of protected areas is linked to the type and form of administration structures applied in each country within the framework of its environmental policy implementation. The administration structure gives citizens the opportunity to take part in decision-making processes concerning the environment and includes partnerships with regional authorities, management bodies, competent ministries, academic institutions and non-governmental organizations. The main principles pertaining to the administration of protected areas are based on international conventions aimed at protecting biodiversity and the natural environment. The present study was conducted at Dadia National Park (NP), in the Evros Prefecture. The stakeholders involved in the administration and management of the NP, namely the park management, the municipality of Soufli and the regional authorities of Evros Prefecture, as well as locals and visitors, were asked their opinion about the effectiveness of administration and management of the park. The results of the study indicate that there are weaknesses affecting the collaboration of the administrative bodies, the locals are not satisfied with the local authorities' operations, and the visitors are not being adequately informed about the relevant bodies and type of administration and management of the NP.

\section{Introduction}

Protected areas constitute the pivotal cornerstones of biodiversity conservation. They are an important field of the planning and application of environmental policy. The main principles governing the administration of such areas are international conventions, such as the Convention of Biological Diversity (Wolfrum 2001; Siebenhüner 2007; Zachrisson 2008), the Convention on the Conservation of Migratory Species of Wild Animals (also known as CMS or the Bonn Convention) (Koester 2002), and the European Council decision on biodiversity and natural habitats, also known as the Bern Convention (Bennett \& Ligthart 2001). The main application mechanisms for this convention are the Directive on the Conservation of Wild Birds (79/409/EEC) and the Habitats Directive (92/43/EEC) within the framework of developing a Natura network of protected areas (Mauerhofer 2008; Zacrisson 2008; Morris 2011); the latter aims to ensure the protection of natural habitats and flora and fauna species of particular ecological interest (Tsantopoulos $\&$ Tsachalidis 2000).

Due to the establishment of Natura 2000, far from preserving natural habitats and important flora and fauna species, also balancing sustainable development for socio-economic and cultural environment is still a prerequisite for effective management (PietrzykKaszyńka et al. 2012). The establishment of a NP is combined with various socio-economic consequences for the surrounding areas, where rural development
Profile

Protected area

Dadia National Park

Mountain range

Rodhopes

Country

Greece

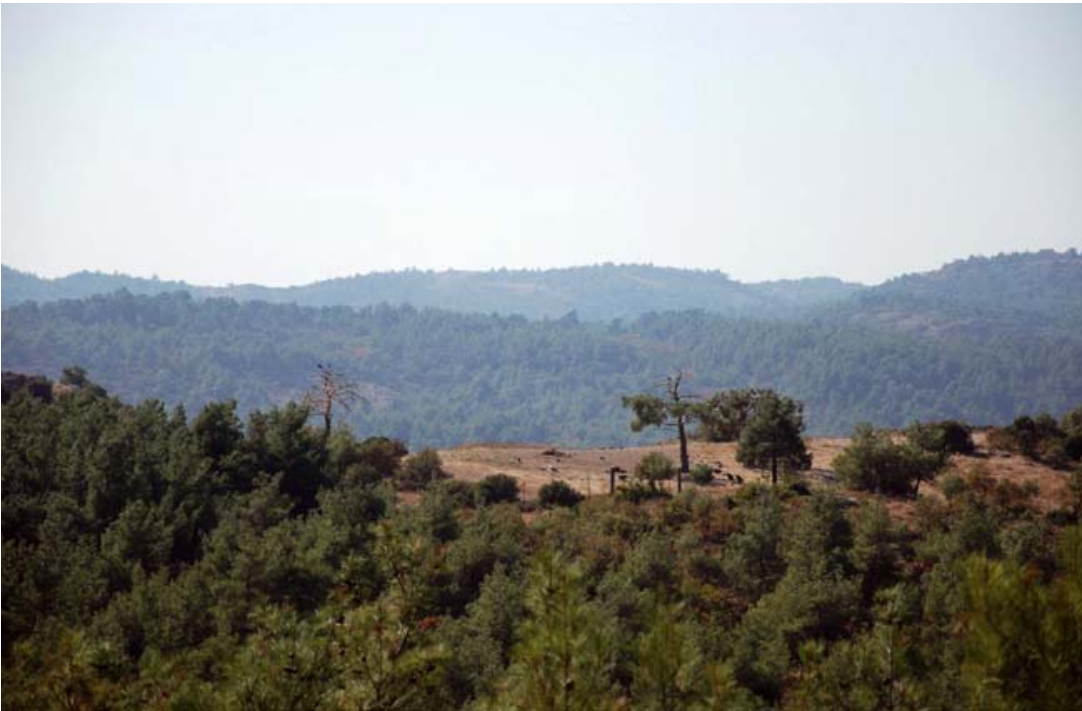

Figure 1 - The raptors' trough in Dadia Forest.

can be achieved (Lassen \& Panagopoulos 2008; Grigoroudis et al. 2012). As Bryan (2012) notes, a new approach has been developed on the connection between natural environment and society. The administration of NPs and protected areas involves regional authorities, management bodies and the relevant ministries, as well as academic institutions or non-governmental environmental organizations (Thompson 2005; Lockwood 2010; Mauerhofer 2011). An understanding of the stakeholders' circumstances and the promotion of programmes that will enhance stakeholders' participation in decision-making procedures should be taken 
into account in order to address, as far as possible, their demands and interests and minimize any conflicts (Andrea et al. 2012a).

According to Foucault (1991), a relationship needs to be established between the citizens, interest groups and administrative bodies, which will continuously evolve. The aim of creating such a relationship of trust is to develop collaborations between these actors through policy planning, structures and processes, aimed at controlling and equally distributing the relevant social benefits (Steward \& Jones 2003). Planning an administrative system that will include participation of all stakeholders in environmental decision-making processes (Clarke 2004) is a new approach in dealing with environmental issues. In fact, this approach studies different viewpoints based on the expectations of the various stakeholders (Dawkins 2004) and offers alternative solutions (Skanavis et al. 2005; Andrea et al. 2012b). As Andrea et al. (2012c) highlight, it is particularly important to create a management model for each case.

In 1986, the Greek Government, in an effort to harmonize Greek environmental policy with that of Europe, passed Law 1650/1986, which introduced changes to its policies on protected areas, including the characterization of new types of protected areas, as well as changes in the type of administration. Moreover, the management of protected areas was assigned to both the Ministry of Agriculture (especially at the Forest Service) and the Ministry of Environment, Planning and Public Works, which turned out to be problematic because of conflicting duties (Kassioumis 1994; Troumbis 1995; Tampakis 2009). Specifically, the Forest Service (Service of the Ministry of Agriculture) was responsible for supervising issues and the Services of the Ministry of Environment, Planning and Public Works were responsible for funding issues (mainly regarding the management of European funding programmes). The initial classification regarding the administrative care of protected areas led to the creation of independent agencies in each region, the Special Administration Authorities for Forest Service (Kassioumis 1994). Nevertheless, in practice, no responsibilities were ever assigned by law to these agencies, and thus the management of national woodland parks was passed on to the relevant forest service (Papageorgiou \& Kassioumis 2005). In the early 1990s, the pressure to apply Council Directive 92/43/ EEC and the imperative need for the effective management of protected areas led to the passing of Law 2742/1999, within the context of Natura 2000 (Dimitrakopoulos et al. 2010), on establishing management bodies as independent management organizations that would be responsible for issues related to environmental protection, supervision, pilot programme application, environmental education, research and sustainable development in each region (Papageorgiou \& Vogiatzakis 2006). The board of each management body would consist of 7 to 11 members / stakeholders representing the local community, experts, competent bodies from the local and central administration and NGO representatives (Papageorgiou \& Kassioumis 2005; Vokou 2012; Apostolopoulou \& Pantis 2009). As Apostolopoulou et al. (2012) note, the establishment of management bodies constitutes a measure of political planning designed to encourage public participation in the management of protected areas.

The aim of this paper is to use a multifaceted approach to present the problems faced by the various administrative bodies with a view to strengthening the effectiveness of the administration and management of Dadia NP by studying the views of all stakeholders.

\section{Study area}

The Eastern Rhodopes Mountains occupy $6000 \mathrm{~km}^{2}$ shared between Bulgaria and Greece, characterized by continental-mediterranean climate, hilly and mountainous landscape, with altitudes ranging from 0 to 1483 metres (Beron \& Popov 2004).

The research area is the National Park of Dadia Lefkimi - Soufli (Figure 1, Figure 2), situated in the Greek part of the Eastern Rhodopes. It is a hilly area with altitudes ranging from 20 to 645 metres (Schindler et al. 2011). Dadia Forest was officially characterized by Joint Ministerial Decision (JMD) 35633 - 911/13-10-2006 as the National Park of Dadia - Lefki$m i-S o u f l i$ Forest, and is one of the country's areas that is managed in the most integrated manner (Arabatzis \& Grigoroudis 2010).

Dadia Forest is the only habitat in Greece that is a breeding ground for the Black Vulture (Aegypius monachus) (Vlachos et al. 1999; Skartsi 2002), which is a rare bird of prey globally identified as an endangered species (Collar et al. 1994; Poirazidis et al. 2004). The forest is also home to other rare birds of prey (Arabatzis \& Grigoroudis 2010; Grigoroudis et al. 2012), such as the Griffon Vulture and the Egyptian Vulture. There are also 36 of the 38 diurnal raptors found there and it is the most important area for the breeding of the Black Stork in Greece. Its vegetation consists of a mixed oak (Quercus frainetto, Quercus cerris, Quercus pubescens) and pine (Pinus brutia, Pinus nigra) forest, which creates a unique ecosystem with rare types of flora and fauna (Poirazidis et al. 2004; Schindler et al. 2011).

In addition, Dadia NP is included in the Greek Natura 2000 list. The total size of the area included in the Natura 2000 network is 43000 hectares, which, according to the JMD of 1980 , covers two strictly protected areas (7290 hectares). Dadia Forest lies within the municipality of Soufli, which is home to 11000 people, who live mainly on animal husbandry, farming, logging and ecotourism. A management body has been established for the NP, the Management Body (MB) of the National Park of Dadia - Lefkimi - Soufli, while administratively the research area belongs to the region of Eastern Macedonia and Thrace (Arabatzis \& Grigoroudis 2010). 


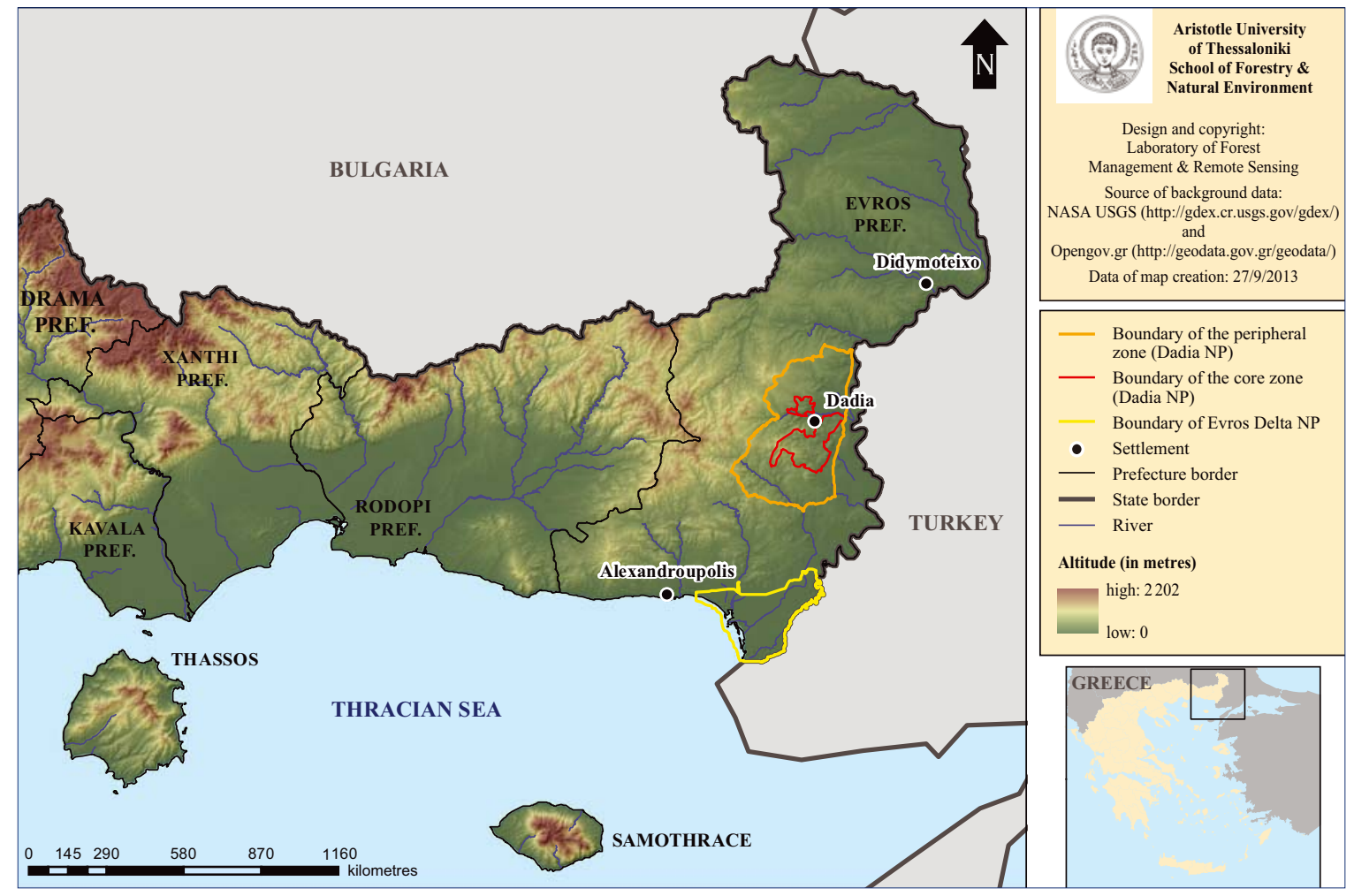

Figure 2 - Map of the study area. http:/ /geodata.gov.gr/geodata/, http://gdex.cr.usgs.gov/gdex/. Designdrawing: Laboratory of Forest Management and Remote Sensing, Aristotle University of Thessaloniki.

Concerning the current institutional framework, the present structure of administration for Dadia NP is represented by the MB, the municipality of Soufli, the regional authorities of Eastern Macedonia and Thrace (RAMTH) and the Forest Service. The MB's responsibilities include running the Information Centre (environmental education), supervision, pilot programme application, field research and sustainable development in the Dadia area. Even though one main responsibility of the $\mathrm{MB}$ is to safeguard and patrol the area, the personnel of the MB does not have the right to independently intervene as an investigator in cases of illegal actions (i. e. they cannot arrest people who break the law and pursue them in court, etc.). This right is exclusive to the Forest Service, who is responsible for upholding the protection status (Forest Law implementation, powers of arrest in cases of violation). The municipality and the RAMTH's duties are focused on a supportive role mainly for the provision of infrastructure. These stakeholders, as well as representatives of the relevant ministries, local cooperations and non-governmental organizations, are members in the administrative council for the management of the NP.

In Evros Prefecture there is another protected area, Evros Delta NP (Figure 2), situated only a few kilometres away from the Dadia NP. Evros Delta NP has been included in the list of protected areas under the International Ramsar Convention and has been characterized as a Special Protection Area, recommended as a Site of Community Interest in the Natura 2000 network.

\section{Methodology}

The present research was conducted using a structured questionnaire on locals and visitors of the Dadia NP. Simple random sampling was used for the locals because of its simplicity and the fact that it requires the least knowledge of the population compared to any other method (Damianou 1999; Kalamatianou 2000; Matis 2001); the municipal rolls were used as sampling frame. Estimates of the population proportion and the standard error $\left(\mathrm{s}_{\mathrm{p}}\right)$ are given by simple random sampling. In order to calculate the size of the sample, pre-sampling was required on a sample size of 50 people. The sample size was estimated for each variable, based on simple random sampling (for probability $(1-\alpha) 100=95 \%, e=0.05)$ and with the finite population correction, since $\mathrm{n}$ is high compared to the size of the population $\mathrm{N}$ for the locals of Dadia (Pagano \& Gauvreau 2000; Kalamatianou 2000; Matis 2001). In total 264 questionnaires were collected.

As there was no existing framework for the visitors before beginning the sampling and we were unable to create one, we chose the cluster sampling method (Siardos 1999; Damianou 1999; Kalamatianou 2000; Matis 2001). In cluster sampling only one list of groups clusters is required, along with the data from the selected clusters (Filias et al. 2000; Benos 1991; Farmakis 1992; Tryfos 1996; Charissis \& Kiochos 1997). The division of the population into clusters leads to reduced sampling costs (Farmakis 1992). The selected clusters were the weekends of the year 2010, when the 


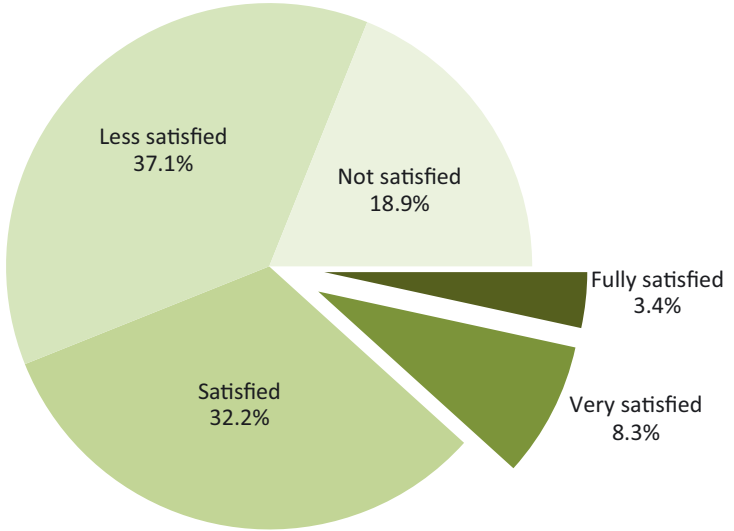

Figure 3 - Locals' satisfaction with their quality of life, $n=264$.

research was conducted (Matsiori 2001). In order to implement this method, the population is divided into $\mathrm{N}$ clusters (52 weekends), of which we take a random sample of $\mathrm{n}$ clusters. From these we collect observations from all units of the selected clusters. The estimate of the population proportion and the standard error $\mathrm{s}_{\mathrm{p}}$, are given by the cluster sampling. Prior to the final sampling, pre-sampling was carried out on five selected clusters. The pre-sampling data were used to calculate the size of the final sample (no. of clusters), with $\mathrm{d}=0.07$ for a probability $(1-\alpha)=95 \%$ (therefore, a corresponding value $z_{\alpha / 2}=z_{0,025}=1.96$ ). The maximum sample size was calculated as being 16 clusters (weekends) for visitors to Dadia. In this way, the most frequently changing variable is estimated to the desired accuracy, while the others are estimated with a greater accuracy than initially defined (Matis 2001). In total 397 questionnaires were collected.

The MB, the municipality of Soufli and the regional authorities of Evros Prefecture, as well as the locals and visitors, were asked their opinion about the effectiveness of administration and management of the NP. The views of the MB, the local and regional authorities were examined in face-to-face interviews with a semi-structured questionnaire. More specifically, those interviewed were the Deputy Head of Evros Prefecture, representing the Regional Authorities of Eastern Macedonia and Thrace (RAMTH), the mayor of Soufli, representing the municipality, and the environmental management officer of the MB of Dadia, representing the latter.

The data for the locals and visitors were collected in 2010 and the analysis was carried out using SPSS. The variables were measured in a nominal and an ordinal scale. The ones measured in the nominal scale consisted of one theme: Locals: gender, age, educational level, marital status, occupation, opinions of the interaction between Dadia NP and Evros Delta NP, views regarding the utilization of subsidies. Visitors: gender, age, educational level, marital status, occupation, connection with the Evros area, permanent residence, willingness to encourage others to visit the NP of Dadia, intention to visit Evros Delta NP.

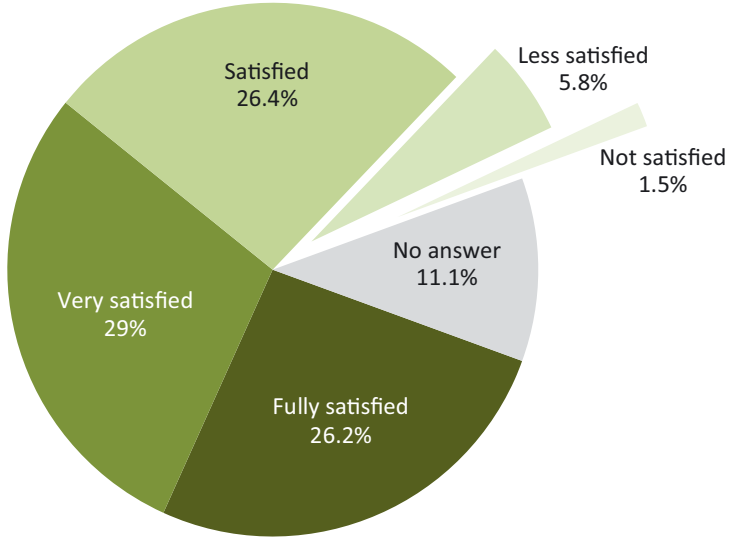

Figure 4 - Visitors' satisfaction with Dadia NP, $n=397$.

In addition, there were variables of more than one theme - multidisciplinary variables, measured on the nominal scale, where the interviewees were provided with the option to give more than one answer. The multidisciplinary variables were: Locals: views of who they consider responsible for the application of the protection status, satisfaction with the promotion of the NP. Visitors: reasons for their visit to the NP, main purpose of their visit to the NP, views of who they consider responsible for the application of the protection status, main reason for not visiting or not intending to visit Evros Delta NP.

Finally, there were variables of one theme, measured in the ordinal scale, with interviewees being restricted to one answer. Locals: satisfaction with their quality of life, satisfaction with the level of information and participation regarding the NP, satisfaction with the application of the protection status, satisfaction with the promotion of the area's historical and cultural assets, satisfaction with the promotion of the NP, satisfaction with the utilization of the provided subsidies. Visitors: frequency of visits to the NP, duration of the trip, satisfaction with their visit to the NP.

The data for the MB, the municipality and RAMTH were collected in 2011. The statistical methods used to interpret the results were descriptive statistics.

\section{Results}

Socio-demographic profile of the locals and visitors of Dadia NP

\section{Locals}

The interviewed locals of Dadia are mainly men $(54.2 \%)$, over 50 years of age $(31.1 \%)$, upper secondary school graduates $(31.1 \%)$, married $(53 \%)$, with no children (33.7\%), mainly farmers, livestock farmers $(14 \%)$, and pensioners (14\%). As regards their satisfaction with their quality of life, six out of ten $(56 \%)$ are less or not at all satisfied (Figure 3). 


\section{Visitors}

Dadia visitors are mainly women $(57.9 \%)$, over 50 years $(50.6 \%)$, university $(30.2 \%)$ or upper secondary school graduates $(25.2 \%)$, married $(70.8 \%)$, with two children (35\%), pensioners $(30.7 \%)$ and civil servants $(20.2 \%)$, who do not have any connection with $\mathrm{Ev}$ ros $(76.1 \%)$, and come from other parts of Greece $(75.3 \%)$. The majority are visiting Dadia for the first time $(77.3 \%)$, on a trip lasting more than one day $(45.6 \%)$ or only a few hours $(33 \%)$. The results show that the visitors are content with their visit to Dadia NP (Figure 4).

The visitors' satisfaction with the NP is also obvious from their intention to encourage others to visit Dadia NP; in fact, $85.6 \%$ intend to do so. According to Arabatzis \& Grigoroudis (2010), in a similar study conducted in Dadia, visitors seem to have been relatively satisfied with the NP, since $88 \%$ of visitors stated that they were very satisfied or satisfied.

Regarding the reason for their visit, most visitors were encouraged by friends or acquaintances to visit the region for the first time or by other factors (Figure 6).

The main purpose of their visit was to observe wildlife or entertainment and recreation (Figure 7).

\section{Effectiveness of the protection status application}

Regarding the application of the protection status in the area, the majority of Dadia locals are less or not at all satisfied (Figure 8).

The population of Dadia seems to consider mainly the local authorities as responsible for the application of the protection status, while $42.4 \%$ opted for the $\mathrm{MB}$ and $34.8 \%$ for the Forest Service (Figure 9).

Visitors see the local authorities and the Forest Service as primarily responsible for applying the protection status, but $33.2 \%$ opted for the MB. They are potentially not aware of the latter's duties regarding the management of the NP (Figure 9).

\section{Promotion and development effectiveness of the area}

Regarding the locals' views on the promotion of the NP by the municipality, only $7.6 \%$ state that they are fully or very satisfied. Furthermore, most of them are less satisfied by the promotion undertaken by the Prefecture (present-day deputy regional authorities) and the Ministry of Tourism Development (Table 1). Regarding the administration bodies of the NP, the promotion of Dadia NP is inadequate. Specifically the MB agrees with the locals' views. The municipality regards the lack of financial tools and political will as the main reasons for the almost non-existent promotion of the NP while suggesting business support by including entrepreneurs on the administration board. The municipality also mentions that there can be no protection of the area without development. According to the RAMTH, it is also important to enhance the joint promotion of the four NPs of Eastern Macedonia and Thrace.

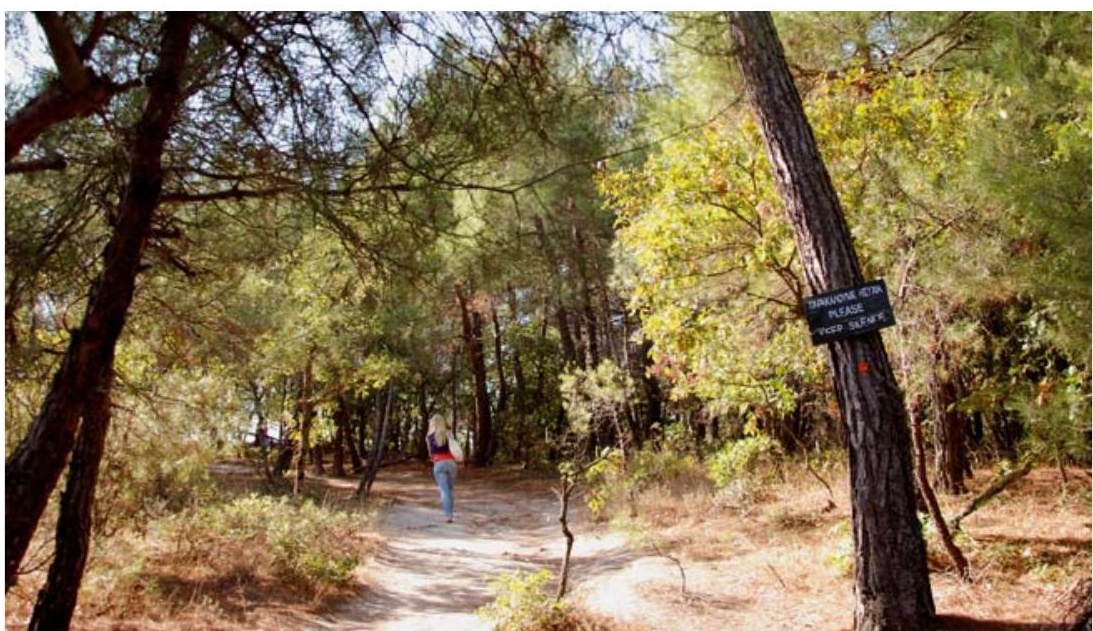

Figure 5 - The pathways in Dadia NP.

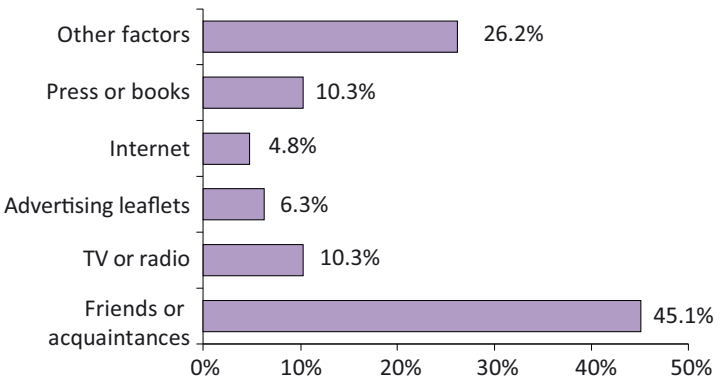

Figure 6 - Visitors' reasons for their visit to Dadia NP. Multiple answers possible, $n=397$.

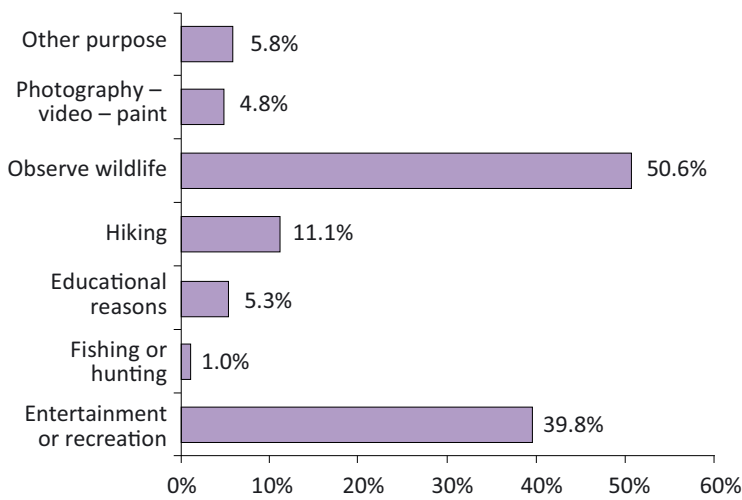

Figure 7 - Visitors' main purpose of their visit to Dadia NP. Multiple answers possible, $n=397$.

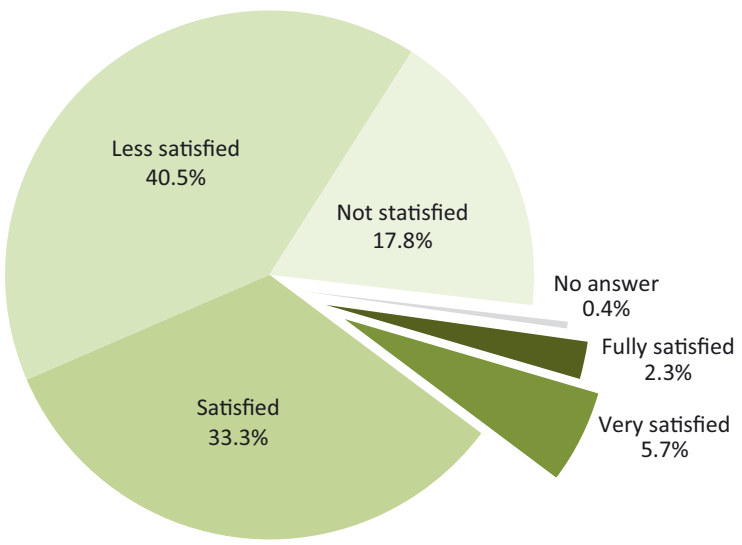

Figure 8 - Locals' satisfaction with the application of the protection status, $n=264$. 


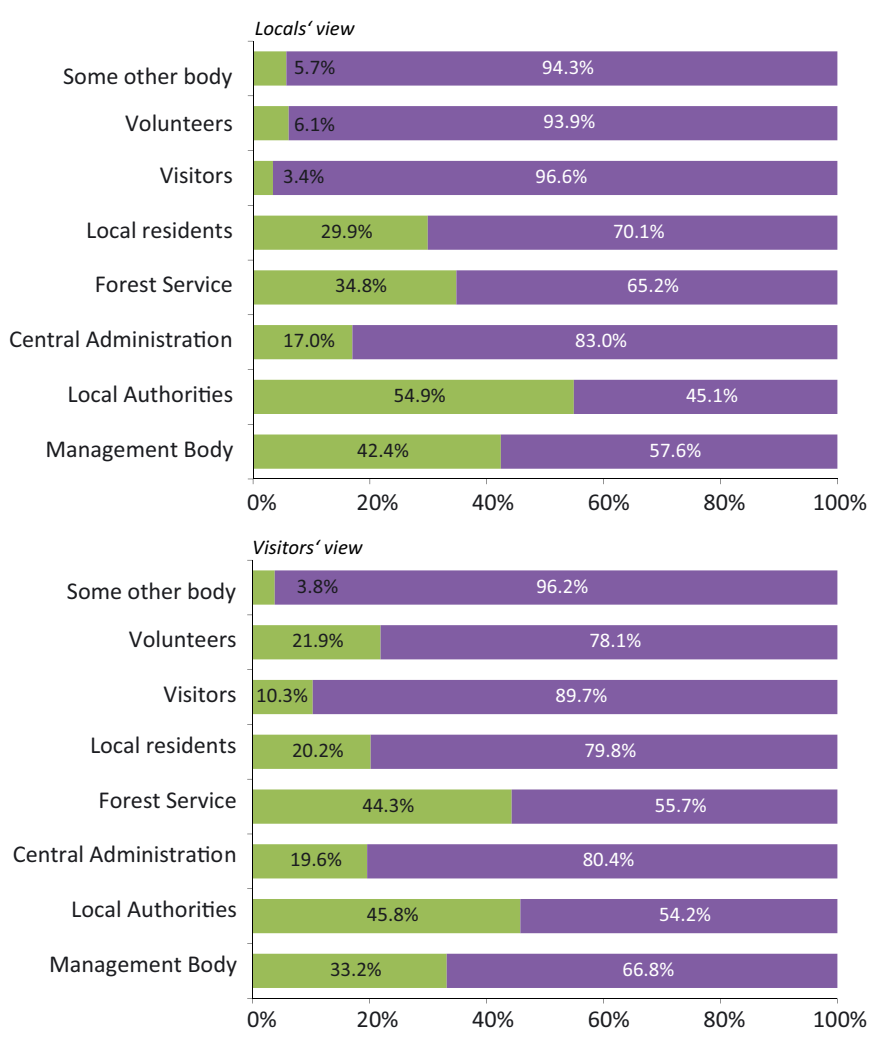

Figure 9 - Locals' (top, $n=264$ ) and visitors' (bottom, $n=397)$ views of who they consider responsible for the application of the protection status. Agree and do not agree.

Regarding the RAMTH, there is a need for better organization in future, while regards that the construction of the museums of Alexandroupoli, Doxipara, Didymoteicho and the archaeological sites of Samothrace (Figure 2) will be a major step towards promoting the historical and cultural assets of the area. According to RAMTH, this can be effectively achieved through international fairs and via the internet. As Petridis (2012) notes, it has submitted an application to UNESCO for Samothrace to be included in the World Network of Biosphere Reserves in order to preserve the natural and cultural heritage of the island within a framework of sustainable development.

The locals are also dissatisfied with the promotion

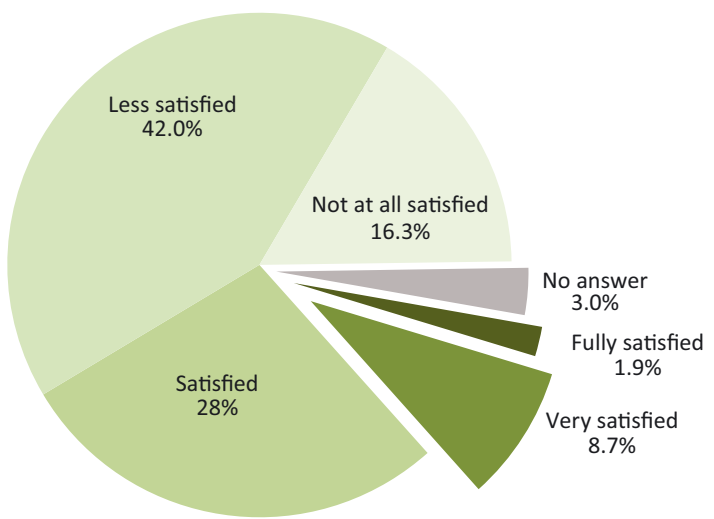

Figure 10 - Locals' satisfaction with the promotion of their area's historical and cultural assets, $n=264$.

of their area's historical and cultural assets (Figure 10). The MB and the municipality share this opinion and especially mention that the lack of funding is also an important factor for the ineffective promotion.

The locals' assessment of the effective promotion of the area is also confirmed by their views on economic growth prospects. More specifically, almost six out of ten are not aware of subsidies provided by the state for tourism development in their region. Not to mention that over half regard the utilization of these assets as insufficient (Figure 12).

Furthermore, the attitude of most locals towards investments in the region is more positive when it involves local villagers (Table 2 ).

There is a consensus between the administrative bodies and the locals, while the MB mentions bureaucratic hurdles impeding the development potential of the area. The municipality and the RAMTH believe that there is room for further development, thus the collaboration of all stakeholders is crucial if tourism development is to become a potential for economic growth.

\section{Management problems}

The locals express their dissatisfaction with the level of information provided on issues related to the NP $(46.6 \%$ very low), which is directly related to their

Table 1 - Locals' satisfaction with the promotion of Dadia NP in \%.

\begin{tabular}{|l|r|r|r|r|r|r|}
\cline { 2 - 7 } \multicolumn{1}{c|}{} & Fully satisfied & Very satisfied & Satisfied & Less satisfied & Not at all satisfied & No answer \\
\hline Municipality & 1.5 & 6.1 & 28.8 & 44.7 & 17 & 1.5 \\
\hline Prefecture & 2.7 & 7.2 & 31.8 & 46.2 & 10.6 & 1.5 \\
\hline Ministry Tourism Development & 0.8 & 5.7 & 26.9 & 42.8 & 20.8 & 3 \\
\hline
\end{tabular}

Table 2 - Locals' views on the investors' origin in $\%$.

\begin{tabular}{|l|r|r|r|r|r|}
\cline { 2 - 6 } \multicolumn{1}{c|}{} & Positive & Quite positive & Quite negative & Negative & No answer \\
\hline Local villagers & 51.9 & 40.9 & 1.9 & 3.8 & 1.5 \\
\hline Other residents of Evros region & 50.8 & 34.1 & 7.6 & 6.1 & 1.5 \\
\hline People from other parts of Greece & 47.3 & 29.9 & 12.5 & 8.3 & 1.9 \\
\hline Foreigners & 41.7 & 26.9 & 9.1 & 19.3 & 3 \\
\hline
\end{tabular}




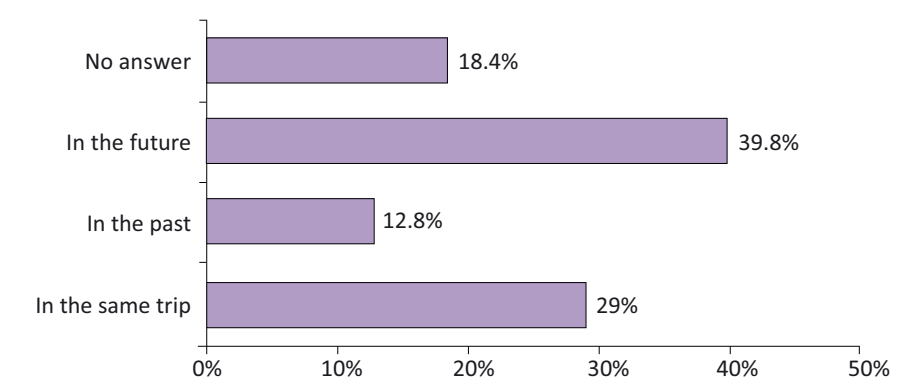

Figure 16 - Visitors' intention to visit Evros Delta NP, $n=397$.

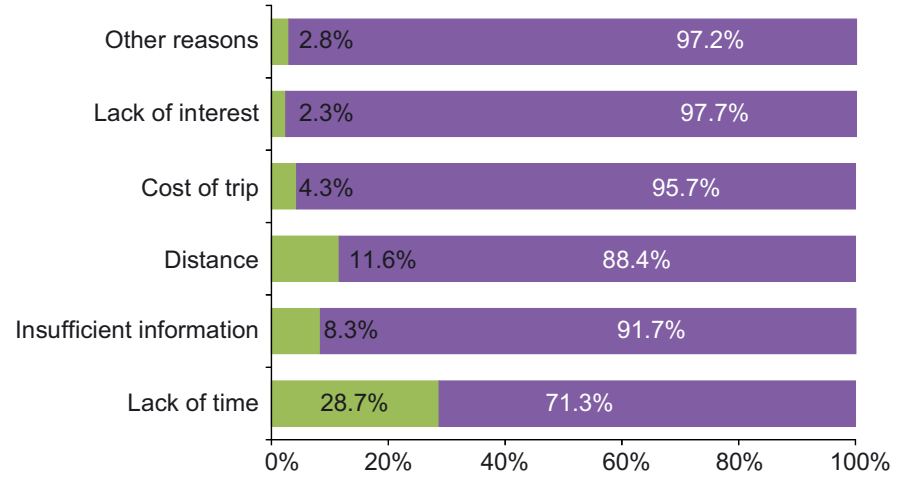

Figure 17 - Visitors' main reasons for not visiting or intending to visit Evros Delta NP, $n=397$. Agree and do not agree.

velopment of the broader area, since both NPs can only affect each other in a positive way. They also think that through effective management there can be a transition from a network of protected areas to a network of development, since the diversity of the two types of habitats, the terrestrial one in Dadia and the wetlands at the Delta offer visitors an integrated view of the regional identity.

Most visitors to Dadia $(39.8 \%)$ intend to visit Evros Delta NP in the future (Figure 16).

Moreover, the main reason mentioned by visitors to Dadia who did not visit or intend to visit Evros Delta NP was lack of time (Figure 17), while the MB also mentions its inadequate promotion.

\section{Discussion \& Conclusions}

Management plans, in order to be effective, should incorporate the locals' views, particularly those related to future local development (Tampakis et al. 2011). Many questions are raised by the locals' dissatisfaction with their quality of life, but their lack of awareness of matters related to Dadia NP and their lack of participation in its decision-making processes were verified by the administrative authorities. In this respect the RAMTH and the municipality suggest that the MB should organize campaigns aimed at raising awareness and participation for the local population.

Moreover, as Wallner and Wiesmann (2009) highlight, locals' participation can ensure the protection status implementation. In Greece the enactment of a large number of laws, provisions, presidential decrees and joint ministerial decisions concerning protected areas reveals the interest of the central administration in the protection of the environment but also creates problems in the application of the law provisions (due to overlapping responsibilities) (Tampakis 2009). This mainly occurs because their implementation involves a large number of administrative bodies with specific responsibilities, such as the Forest Service, the MB, the Hellenic Police and others. For example, in the USA, although 375 protected areas are located in 49 different states, the existing administrative system includes an autonomous body, the National Park Service governing protected areas (Hamin 2001). Another example is the government of the Philippines that also adopted a decentralized administrative system giving gateway communities and NGO's the opportunity to manage protected areas (Dressler et al. 2006). However, in Greece, the establishment of MBs does not provide this kind of self-rule capability. Finland faces similar administrative problems to Greece as it has put into practice a model dependent on the local authorities and the government, which lacks participation of the local community (Selby et al. 2011).

In the case of Dadia, locals as well as visitors are not well informed about the body responsible for the application of the protection status. In particular, they consider the local authorities instead of the MB as the protection body responsible. Thus the insufficient information regarding the application of the protection status reveals that the MB needs to improve its organization and approach via communication programmes aimed at raising awareness on protection issues; it should also ensure locals' participation not only in the relevant decision-making processes, but also in the protection status implementation.

Therefore raising awareness among the stakeholders of the NP on environmental issues and participation in decision-making processes represents operational guidelines towards the adoption of best practices. If this approach is to be successful and to fulfil the aims of protection and sustainable development of the broader region of Evros, another essential step is the establishment of strong cooperation among the administrative bodies, such as the Forest Service, the MB, the municipality, the RAMTH and the relevant ministries. Such cooperation has unfortunately been hindered to date by problems of a bureaucratic nature, lack of coordination, undefined responsibilities and, in the case of the central administration, lack of political will and indifference.

As regards the development of the area, few locals are aware of the existence of subsidies. Both locals and administrative bodies also realize that the valorization of subsidies to date has not led to the desired developmental results. Nonetheless, the current situation points to the imperative need for a change of focus by the administration, first, on the local level and second, nationally, on the inflow of investments. It is important for opportunities to arise for developing and strengthening local businesses, as well as for em- 
ployment opportunities for the local population. Thus, with the help of subsidies, the necessary preconditions will be created to achieve this goal.

Nevertheless, the establishment of Dadia NP has been a significant prerequisite for sustainable development, offering a comparative advantage for the broader tourism development, a fact also confirmed by the majority of visitors, who state wildlife observation as the main reason for their visit. Therefore, mapping development techniques entails organized and sustained promotional plans. However, in the stakeholders' views the promotion of the NP and the historical and cultural assets of the area are inadequate. Moreover, the fact that the visitors' main motivation for visiting the NP is the encouragement of friends or acquaintances reflects its ineffective promotion through the mass media.

Management obstacles, such as irregular funding and staff deficiencies in the MB, both in numbers and training, are operational controversies that impair the administrative and management effectiveness in running the NP. If effective management is to be implemented, protected areas need to have professional staff and funds on a regular basis with the support of both governments and society (Lange \& Müller 2009), not to mention the indeterminate future of the NP after 2015 when EU funding will cease. According to the municipality and the RAMTH, should the MB be dissolved, the park management could be assigned to their services to ensure the necessary funding. This ambiguous argument does not hold up in practice. $\mathrm{Al}$ though the RAMTH and the municipality promise to undertake funding of the NP in case of its dissolution, if this happens, they will claim lack of staff and lack of resources in order to justify ineffective management. It is common for public services in Greece to claim lack of staff to justify administrative ineffectiveness. However, as Hearne and Salinas (2002) note, government funding sources for protected areas tend to be reduced. The latter trend leads to the reformation of management strategies aimed at economic self-rule to ensure their future sustainability, an alternative that is also recommended by the municipality and the RAMTH in the case of Dadia.

Although protected areas are eligible for a large number of national or community programmes they can also seek support from foreign capital investments (Tampakis 2009). The latter alternative solution could possibly have a chance in the case of Dadia. Via a promising perspective, the EU is deemed to be the main means to ensure their economic sustainability until 2020. Any potential bids, however, along with the implementation of such programmes, can only be handled by the MBs. Therefore the merger and dissolution of the MBs will create a gap in the absorption of the relevant funding. In the wake of economic measures imposed by the IMF and the Troika, the latest scenarios in Greece foresee a merger of $29 \mathrm{MBs}$ into $14 \mathrm{MBs}$ in line with the designated regional prefectures. This means that in the broader region of Eastern Macedonia and Thrace, where there are currently four MBs (one for each NP), these will be merged into one. The latest case planned by technocrats is mainly focused on balancing the national budget deficit. In the case of Evros Prefecture, the MB of the neighbouring Evros Delta NP could become the MB of Dadia and the Delta, employing the same scientific personnel (without laying off employees) at lower costs. The function of a united $\mathrm{MB}$ would reduce operational costs such as infrastructure maintenance and fixed costs. Such a scenario would also help to create a network of development, since one park would send visitors to another through a coordinated promotional programme for the whole region.

The potential that already exists for a positive interaction of the stakeholders between the two parks should be strengthened in such a way that we move from a network of protected areas to a network of sustainable development. Visitors' satisfaction with the two NPs is apparent from their willingness to encourage others to visit both parks (Andrea et al. 2012a). Stakeholders also agree that the NPs' existence in the same prefecture functions as an additional incentive for the development of the broader area. Creating such a strategic plan can be achieved through the effective promotion of both parks as a combined tourist destination. This initially means enhanced coordination, improved organization and cooperation between the administrative bodies of both parks. Another prerequisite is their joint cooperation with travel agencies, so that visitors will be informed in advance about the existence of a network of protected areas and the various facilities and activities available at both parks. Thus they would be convinced that visiting both of them will constitute a complete tourist package, offering an enriched experience and a full picture of the natural landscape of Evros.

In a nutshell, adopting best practices entails both economic development and achieving the protection goals. Another suggestion is to increase visitors' satisfaction as satisfied visitors can serve as advertisers for the NP. After all, visitors of the NP have mainly been encouraged by friends or acquaintances to visit the park. Finally, another suggestion is to balance an inflow of investments between ecotourism and protection measures. The first is closely affiliated with infrastructure improvement, especially concerning the road network, while the second is based on security staffing in the NP.

\section{Acknowledgments}

This research has been co-financed by the European Union (European Social Fund - ESF) and Greek national funds through the operational programme Education and Lifelong Learning of the National Strategic Reference Framework (NSRF) - Research Funding Programme: Heracleitus II. Investing in knowledge 
society through the European Social Fund. We are grateful to Dr. Ioannis Gitas and Eleni Dragozi of the Laboratory of Forest Management and Remote Sensing, Aristotle University Thessaloniki for the construction of the study area map.

\section{References}

Andrea, V., S. Tampakis, G. Tsantopoulos \& K. Skanavi 2012a. Interaction and development prospects of Protected Areas: Comparative study of visitors to Dadia and the Evros Delta. Minutes of $5^{\text {th }}$ Panhellenic Conference "Environmental Policy \& Management", 25-27 May 2012, Mytilene. Available at: http://www3. aegean.gr/environment/eeppd/CONF2012.htm (accessed: 01/06/2013)

Andrea, V., S. Tampakis, K. Skanavi \& G. Tsantopoulos 2012b. Expectations of the local population from the management of Protected Areas: Comparative study of the National Parks of Dadia and the Evros Delta, Minutes of $5^{\text {th }}$ Panhellenic Conference "Environmental Policy \& Management", 25-27 May 2012, Mytilene. Available at: http://www3.aegean. gr/environment/eeppd/CONF2012.htm (accessed: $01 / 06 / 2013)$

Andrea, V., S. Tampakis, G. Tsantopoulos \& K. Soutsas 2012c. The role of stakeholders in the sustainable management and development of protected areas: A theoretical approach. Scientific Journal of the Department of Forestry and Environmental Management and Natural Resources, DUTH, in honour of Professor E. Tsachalidis 3: 253-269.

Apostolopoulou, E. \& D.J. Pantis 2009. Conceptual gaps in the national strategy for the implementation of the European Natura 2000 conservation policy in Greece. Biological Conservation 142 (1): 221-237.

Apostolopoulou, E., E. Drakou \& K. Pediaditi 2012. Participation in the management of Greek Natura 2000 sites: Evidence from a cross-level analysis. Journal of Environmental Management 113: 308-318.

Arabatzis, G. \& E. Grigoroudis 2010. Visitors' satisfaction, perceptions and gap analysis: The case of Dadia - Lefkimi - Souflion National Park. Forest Policy Economics 12 (3): 163-172.

Bennett, G. \& S. Ligthart 2001. The implementation of international nature conservation agreements in Europe: the case of the Netherlands. European Environment 11 (3): 140-150.

Benos, K. 1991. Sampling Methods and Techniques. Stamoulis publications.

Beron, P. \& A. Popov 2004. Biodiversity of Eastern Rhodopes (Bulgaria and Greece). Biodiversity of Bulgar$i a$. 2. Pensoft \& National Museum of Natural History.

Bryan, S. 2012. Contested boundaries, contested places: The Natura 2000 network in Ireland. Journal of Rural Studies 28 (1): 80-94.

Charisis, K. \& P. Kiochos 1997. Sampling Theory \& Applications. Athens.
Clarke, T. 2004. Introduction: theories of governance - reconceptualising corporate governance theory after the Enron experience. In: Clarke, T. (ed.), Theories of Corporate Governance. First edition, London.

Collar, N.J., M.J. Crosby \& A.J. Stattersfield 1994. Birds To Watch 2: The World List of Threatened Birds, BirdLife International, UK. BirdLife Conservation Series No. 4. Cambridge.

Damianou, Ch.Ch. 1999. Sampling Methodology: Techniques and applications. $3^{\text {rd }}$ edition.

Dawkins, S. 2004. Corporate responsibility: the communication challenge. Journal of Communication Management 9: 108-119.

Dimitrakopoulos, G.P., N. Jones, T. Iosifides, I. Florokapi, O. Lasda, F. Paliouras \& I.K. Evangelinos 2010. Local attitudes on protected areas: Evidence from three Natura 2000 wetland sites in Greece. Journal of Environmental Management 91 (9): 1847-1854.

Dressler, H.W., A.K. Christian \& C.T. Meredith 2006. The Politics of decentralizing national parks management in the Philippines. Political Geography 25 (7): 789-816.

Farmakis, N. 1992. Introduction to Sampling. Thessaloniki.

Filias, V., P. Pappas, M. Antonopoulou, O. Zarnari, I. Magganara, M. Meimaris, I. Nikolakopoulos, E. Papachristou, I. Perantzaki, E. Sampson \& E. Psychogios 2000. Introduction to Social Research Methodology and Techniques. Athens.

Foucault, M. 1991. Governmentality. In: Burchell, G., C. Gordon \& P. Miller (eds.), The Foucault Effect. London.

Grigoroudis, E., G. Arabatzis \& S. Tsiantikoudis 2012. Multivariable analysis of Dadia-Lefkimi-Soufli National Park visitors' satisfaction. Journal of Food, $A g$ riculture and Environment 10 (3-4): 1256-1264.

Hamin, M.E. 2001. The US National Park Service's partnership parks: collaborative responses to middle landscapes. Land of Use Policy 18 (2): 123-135.

Hearne, R.R. \& Z.M. Salinas 2002. The use and choice experiments in the analysis of tourist preferences for ecotourism development in Costa Rica. Journal of Environmental Management 65: 153-163.

Kalamatianou, A.C. 2000. Social Statistics, One-dimensional Analysis Methods. Athens.

Kassioumis, K. 1994. The protection of nature. Geotechnical Scientific Issues 5 (3): 58-74.

Koester, V. 2002. The five global biodiversity-related conventions: a stocktaking. Review of European Community and International Environmental Law 11 (1): 96-103.

Lassen, S.M. \& T. Panagopoulos 2008. Environmental awareness at the protected area of Brilhante, Brazil. International Journal of Energy and Environment 2 (1): 1-8.

Lockwood, M. 2010. Good governance for terrestrial protected areas: A framework, principles and performance outcomes. Journal of Environmental Management 91 (3): 754-766. 
Matis, K. 2001. Forest Sampling. Democritus University of Thrace, Xanthi.

Matsiori, S. 2001. Valuation of natural forest resources in the greater region of the university forest in Pertouli. $\mathrm{PhD}$ thesis. Department of Forestry and the Natural Environment, AUTh. Thessaloniki.

Mauerhofer, V. 2008. Conservation of wildlife in the European Union with a focus on Austria. In: Panjwani, R. (ed.), Wildlife Law: A Global Perspective: 1-55. Chicago.

Mauerhofer, V. 2011. A bottom-up 'ConventionCheck' to improve top-down global protected area governance. Land Use Policy 28 (4): 877-886.

Morris, R.K.A. 2011. The application of the Habitats Directive in the UK: compliance or gold plating? Land Use Policy 28 (1): 361-369.

Pagano, M. \& K. Gauvreau 2000. Principles of Biostatistics.

Papageorgiou, K. \& K. Kassioumis 2005. The national park context in Greece. Park users' perspectives of issues in park administration 13 (4): 231-246.

Papageorgiou, K. \& N.I. Vogiatzakis 2006. Nature protection in Greece: an appraisal of the factors shaping integrative conservation and policy effectiveness. Environmental Science and Policy 9 (5): 476-486.

Pietzyk-Kaszyńka, A., J. Cent, M. GrozińskaJurczak \& M. Szymsńska 2012. Factors influencing perception of protected areas - The case of Natura 2000 in Polish Carpathian communities. Journal for $\mathrm{Na}$ ture Conservation 20 (5): 284-292.

Petridis, P. 2012. Perception, attitudes and involvement of local residents in the establishment of a Samothraki Biosphere Reserve, Greece. eco.mont 4 (1): 59-64.

Poirazidis, K., V. Goutner, T. Skartsi \& G. Stamou 2004. Modelling nesting habitat as a conservation tool for the Eurasian black vulture (Aegypius monachus) in Dadia Nature Reserve, northeastern Greece. Biological Conservation 118 (2): 235-248.

Schindler, S., N. Curado, C.S. Nikolov, E. Kret, B. Cárcamo, G. Catsadorakis, K. Poirazidis, T. Wrbka \& V. Kati 2011. From research to implementation: Nature conservation in the Eastern Rhodopes mountains (Greece and Bulgaria), European Green Belt. Journal for Nature Conservation 19 (4): 193-201.

Selby, A., L. Petäjistö \& M. Huhtala 2011. The realisation of tourism business opportunities adjacent to three national parks in southern Finland: entrepreneurs and local decision-makers matter. Forest Policy and Economics. 13 (6): 446-455.

Siardos, C.K. 1999. Multivariate Statistical Analysis Methods, Part I, Study of the Relations Between Variables. Thessaloniki.

Siebenhüner, B. 2007. Administrator of global biodiversity: the secretariat of the convention on biological diversity. Biodiversity Conservation 16 (1): 259-274.

Sims, R.E.K. 2010. Conservation and development: Evidence from Thai protected areas. Journal of Environmental Economics and Management 60: 94-114.
Skanavis, C., M. Sakellari \& V. Petreniti 2005. The potential of free choice for environmental participation in Greece. Environmental Education Research 11 (3): 321-333.

Skartsi, T. 2002. Annual Technical Report Population Estimation and Breeding Success of the Black Vulture in 2002. Monitoring Plan of Dadia Forest 2002. WWF-Greece. Athens.

Steward, J. \& G. Jones 2003. Renegotiating the Environment. Sydney.

Thompson, N. 2005. Inter-institutional relation in governance of England's National Parks: A governmentality perspective. Journal of Rural Studies 21 (3): 323-334.

Tampakis, S. 2009. Protected areas: Policies of the past and the present, Introduction to Forestry and Environmental Science. In: Manolas, E. (ed.), Issues of Forestry and Management of the Environment and Natural Resources I: 151-162.

Tampakis, S., E. Manolas \& V. Tampakis 2011. Prospect and impasses in the sustainable development of the island of Skiathos: The residents' views, Environmental Protection Policies. Issues of Forestry and Management of the Environment and Natural Resources 3: 202-216.

Troumbis, A. 1995. Ecological networks in Greece. Landscape 95: 51-62.

Tryfos, P. 1996. Sampling Methods for Applied Research: Text and Cases. Canada.

Tsantopoulos, C. \& E. Tsachalidis 2000. Management of the wetlands of Ismarida lake and the Evros river delta: Comparative study of the educational level and environmental behaviour of residents living near wetlands. Minutes of $9^{\text {th }}$ Panhellenic Forestry Conference, 17-20 October: 372-384. Kozani.

Vlachos, C.G., D.E. Bakaloudis \& G.J. Holloway 1999. Population trends of black vulture Aegypius monachus in Dadia Forest, northeastern Greece following the establishment of a feeding station. Bird Conservation International 9: 113-118.

Vokou, D. 2012. Policies for biodiversity preservation in Greece. National System of protected areas and Natura 2000 Committee. Minutes of $5^{\text {th }}$ Panhellenic Conference "Environmental Policy \& Management", 25-27 May 2012, Mytilene. Available at: http://www3. aegean.gr/environment/eeppd/CONF2012.htm (accessed at: 01/06/2013)

Wallner, A. \& U. Wiesmann 2009. Critical Issues in Managing Protected Areas by Multi-Stakeholder Participation - Analysis of a Process in the Swiss Alps. eco.mont 1 (1): 45-50.

Wolfrum, R. 2001. The Convention on Biodiversity: obligations and enforcement mechanisms. In: Zhenghua, T. \& R. Wolfrum (eds.), Implementing International Environmental Law in Germany and China. International Environmental Law and Policy Series, Kluwer Law International 59: 31-39.

Zachrisson, A. 2008. Who should manage protected areas in the Swedish mountain region? A survey 
approach to co-management. Journal of Environmental Management 87 (1): 154-164.

\section{Authors}

Veronika Andrea

$\mathrm{PhD}$ at the Department of Forestry and Management of the Environment and Natural Resources at Democritus University of Thrace. Her main research interests are: forest and environmental policy, environmental policy issues and protected areas.

\section{Stilianos Tampakis}

is associate professor at the department of Forestry and Management of the Environment and Natural Resources at Democritus University of Thrace. His research interests are forest and environmental policy. He has published over 100 articles in international and Greek journals and proceedings.

\section{Georgios Tsantopoulos}

is an assistant professor at the Department of Forestry and Management of the Environment and
Natural Resources, Democritus University of Thrace, Greece. He has published widely in various international journals, including the Environmental Politics, Renewable and Sustainable Energy Reviews.

\section{Garyfallos Arabatzis}

is associate professor (2013 - present) at the Department of Forestry and Management of the Environment and Natural Resources at Democritus University of Thrace. His research interests are: natural resource economics and policy, forest valuation, regional development.

Department of Forestry and Management of the Environment and Natural Resources, Democritus University of Thrace, Pantazidou 193, 68200 Orestiada, Greece

(C) of all pictures: Veronika Andrea 